\title{
MODELOS DE FORMAÇÃO PARA O ENSINO DA ESCRITA EM PORTUGAL E NO BRASIL'
}

\author{
Luísa Álvares Pereira * \\ Luciana Graça ** \\ Anderson Carnin ***
}

\begin{abstract}
RESUMO
Os modelos atualmente adotados, quer em Portugal quer no Brasil, no contexto da universitarização da formação de professores para a competência de escrita, em particular, têm proposto novas formas de agir didático, nomeadamente, no sentido de uma articulação entre a formação e o próprio contexto escolar. Após uma breve apresentação de algumas considerações sobre a formação de professores para o ensino da língua, em geral, e para o ensino da produção escrita, em particular, passaremos à apresentação de três processos de formação contínua para o ensino da produção de textos escritos, terminando com algumas considerações que podem ser extraídas de todo esse processo, e que nos permitem equacionar princípios-chave para a definição de um modelo de formação de professores para o ensino dessa competência.
\end{abstract}

Palavras-chave: Formação de professores. Gêneros de texto. Escrita.

\section{ABSTRACT \\ TRAINING MODELS FOR TEACHING WRITING IN PORTUGALAND IN BRAZIL}

Teacher training models currently used, both in Portugal and in Brazil, in the context

\footnotetext{
${ }^{1}$ Este texto foi produzido no âmbito dos seguintes projetos: 1) projeto de investigação PROTEXTOS - Ensino da Produção de Textos no Ensino Básico, coordenado pela Professora Doutora Luísa Álvares Pereira, e financiado pela Fundação para a Ciência e Tecnologia (PTDC/CPE-CED/101009/2008) e pelo Programa COMPETE: FCOMP-01-0124-FEDER-009134 (Programa Operacional Temático Factores de competitividade do Quadro Comunitário de Apoio III e comparticipado pelo Fundo Comunitário Europeu FEDER); 2) projeto de pós-doutoramento"Formação,investigação e ensino da escrita: uma articulação indispensável para a profissionalização docente financiado pela Fundação para a Ciência e a Tecnologia (SFRH/BPD/75952/2011) e com supervisão científica de Luísa Álvares Pereira e Joaquim Dolz; 3) Projeto "Por uma formação continuada cooperativa para o desenvolvimento do processo educativo de leitura e produção textual escrita no Ensino Fundamental", apoiado pela Capes/Inep-Programa Observatório da Educação, Edital 38/2010, sob coordenação da Professora Doutora Ana Maria de Mattos Guimarães.

* Doutora em Didática do Português pelo programa de Pós-Graduação em Educação da Universidade de Aveiro (UA). Professora auxiliar do departamento de Educação da Universidade de Aveiro (UA). Linhas de pesquisa: Ensino da Escrita - Produção de gêneros de textos na escola. Grupo de pesquisa a que pertence: Protextos - CIDTFF/UA. Endereço para correspondência: Departamento de Educação - Universidade de Aveiro. Campus Universitário de Santiago. CEP: 3810-193. Aveiro - Portugal. lpereira@ua.pt

** Doutora em Didática pelo programa Pós-Graduação em Educação - Universidade de Aveiro (UA). Pós-doutoranda em Didática - Ciências da Educação, com bolsa da Fundação para a Ciência e a Tecnologia (SFRH/BPD/75952/2011), no Departamento de Educação da Universidade de Aveiro. Linhas de pesquisa: Ensino da Escrita - Produção de gêneros de textos na escola. Grupo de pesquisa a que pertence: Protextos - CIDTFF/UA. Endereço para correspondência: Departamento de Educação - Universidade de Aveiro. Campus Universitário de Santiago. CEP: 3810-193. Aveiro - Portugal. lucianagraca@ua.pt

*** Mestre e doutorando em Linguística Aplicada na Universidade do Vale do Rio dos Sinos (UNISINOS/Capes) Campus São Leopoldo-RS. Estágio de doutoramento sanduíche (PDSE/Capes) na Universidade de Aveiro. Linhas de pesquisa: Interação e Práticas Discursivas - Linguagem e Práticas Escolares. Endereço para correspondência: Avenida Unisinos, n. 950, São Leopoldo-RS. CEP: 93022-000. anderson.carnin@gmail.com
} 
of the universitarization of teacher training in the competence of writing, in particular, have proposed new ways of teaching, especially in the sense of links between teacher training and the school context. After a brief presentation of some considerations of teacher training for language teaching in general and teaching of writing in particular, we present three processes of training for teaching the production of written texts. We conclude making some considerations that can be drawn from this process and that allow us to reach key principles for the definition of a model for teacher training for this competence.

Keywords: Teacher training. Text genres. Writing.

\section{Considerações iniciais}

Os modelos de formação atualmente adotados, quer em Portugal quer no Brasil, no contexto da universitarização da formação de professores de línguas, em geral, e da competência de escrita, em particular, têm insistido na relevância da articulação entre a formação e o próprio contexto escolar, defendendo-se assim a centralidade da experiência em sala de aula nos próprios processos de (trans) formação profissional. Na verdade, e independentemente de várias explicações complexas para a dificuldade atual em saber como lidar com as crianças de hoje, não podemos deixar de interrogar as melhores formas de melhorar os processos de ensino e de aprendizagem da escrita. Resposta esta que, naturalmente, teria também então de contemplar uma reflexão sobre o próprio processo de formação de professores. E, a este respeito, múltiplas são as interrogações que podem ser formuladas: a) qual o modelo de formação a escolher?; b) privilegiar a componente teórica e/ou valorizar a vertente prática?; c) quais as práticas efetivas de ensino a adotar?; d) e como se pode perceber o que foi efetivamente integrado, na prática de sala de aula, pelos professores em formação ${ }^{2}$

Essas interrogações declinam-se em três principais partes: 1) apresentação de importantes considerações sobre a formação de professores para o ensino da língua, em geral, e para o ensino da produção escrita, em particular, destacando-se algumas das mais relevantes questões para as quais se foi procurando dar resposta; 2) apresentação de três processos de formação contínua para o ensino da produção de textos escritos; e 3) apresentação

2 Consultar, por exemplo, o número 13 da revista Dyptique (DOLZ; PLANE, 2008). de algumas das principais ilações que podem ser extraídas de todo esse processo e que nos permitam equacionar possíveis modelos de formação de professores para o ensino dessa competência, a fim de que os anos que aí chegam sejam, decididamente, os anos do ensino da produção escrita.

\section{A transposição dos saberes teóricos em saberes práticos}

A importância decisiva atribuída por investigações científicas aos processos de formação docente, em razão da estreita ligação entre a preparação dos professores e a qualidade dos programas educativos e o próprio desempenho dos alunos, tem contribuído para incrementar o interesse pelo estudo da influência dos saberes (re)construídos na e pela formação de professores, nas suas próprias práticas, in loco. Afinal, da existência de novos programas não decorre, necessariamente, tal mudança. Como sabemos, essa mesma passagem de conhecimentos não corresponde a uma transposição linear dos saberes implicados, sendo perturbada por diversos filtros. ${ }^{3}$ Em outras palavras, acontece que, na cadeia da transposição didática, há a registar, designadamente, os efeitos provocados pela cultura escolar, pela cultura profissional dos professores e pela própria forma como são adotados os manuais e os restantes materiais didáticos (CASTRO; SOUSA, 1998). Todos estes elementos são responsáveis pela

\footnotetext{
3 Leia-se, a título exemplificativo, o artigo de Fabienne Rondelli (2010) La cohérence textuelle: pratiques des enseignants et théories de référence, que se interessa pelos comentários feitos por professores sobre a coerência de textos narrativos escritos pelos respectivos alunos. A partir de exemplos concretos, o artigo mostra que os professores avaliam os textos numa tensão entre o apelo para determinadas noções linguísticas muito didatizadas e a sua relação pessoal com o texto.
} 
inscrição de professores e de alunos em determinadas disposições sociais e didáticas indutoras de representações e de preocupações específicas, no que às suas conceções e práticas em sala de aula diz respeito. Torna-se necessária, assim, uma convergência de outras tantas condições, tais como, em particular, a de fazer com que os docentes sintam-se como uma parte importante desse mesmo processo, sentindo, ainda, alguma segurança em todo ele. Daí que outras questões, ainda mais específicas, devam também ser equacionadas: i) de que forma ocorre a transposição dos saberes adquiridos na formação para a prática (quais os saberes recuperados, transformados e/ou eliminados, quando da atuação docente, em sala de aula)?; ii) de que forma(s) pode a formação produzir verdadeiros efeitos nas práticas docentes, de modo a ultrapassar-se o mero nível de integração, in loco, de uma ou de outra atividade fortuita e considerada como mais interessante?

Ora, a complexidade associada a essa articulação entre saberes teóricos e práticos é responsável pela definição de múltiplos modelos de formação, numa procura incessante do modelo: de um modelo de formação que atualize, de forma efetiva, as propostas consignadas nos documentos programáticos oficiais, no que ao ensino da escrita diz respeito, e em que a sistematicidade da ação didática do professor, em sala de aula, assume um papel de indiscutível destaque. Contudo, muitos trabalhos de investigação continuam a revelar que as práticas e os manuais ainda adotam, por vezes, um paradigma de trabalho em que a escrita, concebida como produto uniforme e acabado, surge no fim da linha, relativamente a outras competências. De qualquer forma, e apesar da lentidão deste processo, começou já a configurar-se, tanto em Portugal como no Brasil, um contexto favorecedor da emergência de uma Didática da Escrita, designadamente, também por meio dos estudos sobre o texto e o seu funcionamento. Ora, estes estudos, ao destacarem a visão global do texto enquanto unidade, e mostrando a dependência de todos os seus elementos relativamente a esta mesma globalidade, revelaram, precisamente, como a estruturação textual e a organização discursiva se instituem como instrumentos de observação e como grades de análise eficazes para a própria atividade didática. E, nesta senda, a tipologia específica proposta por Adam (1992) também se constituiu como um referencial determinante para a produção de materiais renovadores no ensino da produção escrita. Todavia, durante muito tempo, nem todas essas dimensões estavam acessíveis a muitos dos professores, formados num paradigma formalista e enformados por uma configuração didática em que dominava a doxa lógico-gramatical (BRONCKART; BULEA; POULIOT, 2005), caracterizada por um acesso ao domínio da produção escrita por meio da conjugação da leitura de autores consagrados e de exercícios de gramática.

Assim, apesar do que ditam os documentos oficiais, a despeito da existência de textos sobre Didática que assumem a importância do ensino explícito da escrita e também apesar do que os estudos sobre o texto e a competência textual já revelaram sobre o funcionamento e a organização dos vários textos (COUTINHO, 2003; KOCH; ELIAS, 2006), há ainda questões que se colocam, ao procurar erigir-se um modelo de formação adequado: afinal, não só perduram as dificuldades em transpor para a prática um ensino da escrita realizado com uma orientação de produção de textos, enquanto práticas sociais diversificadas e com composições específicas, como também não basta a mera integração de tais conteúdos no processo formativo. Daí que seja importante definir não só o núcleo duro de saberes a tratar como também a forma de transmissão destes mesmos saberes aos professores: adotar uma transmissão de saberes sem qualquer interferência da experiência ou uma reflexão sobre as próprias práticas?

As investigações atuais têm defendido que a experiência e a reflexão sobre as práticas são decisivas para a construção do conhecimento docente, como também defendem Bulea e Bronckart (2010, p. 45): "une étroite articulation entre dispositifs classiques de transmission de savoirs et dispositifs d'analyse des pratiques", numa perspectiva de conjugação eficaz entre o praxiológico e o epistémico. E, na verdade, importa estabelecer um equilíbrio entre o domínio teórico das noções e regras mobilizadas pelos programas e a análise de práticas a fim de desenvolver a própria capacidade de encontrar objetos teóricos nos objetos de ensino tal como circulam em sala de aula a capacidade de identificar obstáculos na realização de um determinado 
projecto de ensino - resistência dos alunos, fatores socioculturais, condições de funcionamento da aula - e a capacidade de identificar as técnicas e os "truques" que os próprios professores também ativam, a fim de ultrapassar as dificuldades identificadas (BULEA; BRONCKART, 2010). O que está aqui em causa, portanto, é a não adoção de uma concepção instrumental, aplicacionista e seguidista da prática, que deve, antes, ser percepcionada como aquilo que efetivamente é: experiência. A respeito, precisamente, da formação para a excelência profissional, Maria do Céu Roldão (2003) advoga, numa ótica de reforço da exigência e da qualidade científicas da formação, a ideia do professor como um verdadeiro intelectual, profissional da cultura e do conhecimento. Por outro lado, também se colocam aqui a questão dos próprios materiais que reduzem a informação e a da própria simplificação excessiva dos campos de saberes intelectuais. Defende-se, assim, uma formação centrada, por um lado, num programa de saberes transmitidos por meio de dispositivos clássicos e a própria análise de práticas, numa perspetiva de construir uma formação voltada, enfim, para a capacidade de conhecer, de pensar sobre e de agir de forma fundamentada (ALARCÃO, 2003).

Os três seguintes dispositivos de formação constituem-se como uma tentativa de resposta a todas essas interrogações e complexidades.

\section{2. (Três) Processos de formação para o ensino da produção de textos}

\subsection{Programa Nacional de Ensino de Por- tuguês (PNEP)}

O Programa Nacional de Ensino de Português (2006-2010) consistiu, grosso modo, num dispositivo de formação de formadores para o ensino da língua escrita, tendo tido como objetivo essencial a melhoria das aprendizagens das crianças, no que diz respeito à língua portuguesa. A formação esteve centrada nas escolas e visou atender às necessidades concretas sentidas pelos respectivos docentes do $1^{\mathrm{o}}$ ciclo do Ensino Básico. Por outro lado, também se procurou quer estabelecer uma articulação estreita entre as escolas de formação e as escolas básicas, quer deixar, no terreno, uma rede articulada de formadores capazes de dinamizar a própria formação nas suas escolas. No que se refere à organização da formação, distinguem-se dois grandes grupos, ainda que trabalhando em permanente sinergia: o grupo A, formado pela Coordenação Regional e pelos formadores residentes; e o grupo B, constituído pelo formador residente e pelos formandos do Agrupamento (entre 10 e 15 formandos). Ao grupo A couberam as sessões de aprofundamento regionais, o apoio à formação no terreno - apoio individualizado e/ou dado em reuniões do grupo de formadores -, as sessões plenárias regionais e o próprio acompanhamento em linha. Ao grupo B couberam o acompanhamento tutorial, as oficinas temáticas e as sessões plenárias regionais. Em relação ao acompanhamento tutorial, visou apoiar-se, diretamente, o docente na planificação, na realização e na reflexão/avaliação de sequências de ensino construídas para o ensino da língua. As oficinas temáticas, por sua vez, e com periodicidade quinzenal, visaram à exploração e a elaboração de materiais didácticos e de avaliação, com base no próprio debate sobre temáticas distintas, que foram consideradas como essenciais: o desenvolvimento da linguagem oral, o ensino da leitura, o ensino da expressão escrita e a utilização do computador na aprendizagem da língua. O processo de formação para o ensino da escrita decorreu, em traços gerais, da seguinte forma: 1) a Coordenadora, de uma Instituição Pública de Ensino Superior, e os professores formadores selecionados preparam, numa oficina de trabalho, a formação mais formal sobre o ensino da produção de textos escritos; 2) segue-se o trabalho de adaptação desta mesma formação, pelos próprios formadores, em razão dos seus contextos específicos de trabalho; 3) com o apoio da Brochura PNEP relativa à escrita como dimensão textual (BARBEIRO; PEREIRA, 2007), os professores formadores realizam, junto dos colegas, a formação prevista, discutindo-se os conhecimentos divulgados; 4) segue-se o acompanhamento, no terreno, das atividades realizadas pelos formandos com os seus alunos, a partir da reflexão em conjunto sobre a temática específica e também com base na já referida Brochura; 5) as atividades efetivamente realizadas, em sala de aula, são posteriormente reelaboradas no grupo de formadores, em conjunto com a Coordenadora, com base, novamente, nos respectivos enquadramentos teóricos; 6) finalmen- 
te, procede-se à publicação, também em formato de brochura, de algumas dessas mesmas atividades reelaboradas. Naturalmente, todo este trabalho só foi possível graças, designadamente: à realização de sessões presenciais conjuntas, com apresentação e discussão sobre as temáticas selecionadas e com melhoramento e divulgação de materiais pedagógicos e de avaliação; à própria experimentação de materiais pedagógicos e de avaliação nas escolas; e, igualmente, ao trabalho autônomo de reflexão e de aprofundamento. E, na realidade, a utilização e a concessão de materiais adequados foram, de fato, deveras decisivas para o reforço do desenvolvimento desses mesmos conhecimentos teóricos, por parte dos formandos (SIM-SIM, 2012).

\subsection{Protextos - Ensino da Produção de Textos no Ensino Básico \\ O projeto de investigação Protextos - Ensino da} Produção de Textos no Ensino Básico (2010-2013) - visa, em traços gerais, ultrapassar uma situação em que a informação disponível - nomeadamente, a relativa a modelos processuais de escrita. Sem o apoio de uma modelização didática consistente e de instrumentos específicos, ainda não produziu os efeitos desejáveis, em nível do currículo e das práticas de ensino da escrita. Partindo-se da premissa de que é necessário reforçar a atenção a uma fase crucial da escrita, a da aprendizagem da textualização - visto que as respectivas operações são indissociáveis da natureza específica do (gênero de) texto a produzir, da relação que o aluno vai estabelecendo com a escrita e do saber específico sobre esse tipo de escrita, nela incluídas as próprias estruturas gramaticais a mobilizar-, foram concebidas oficinas de formação sobre diferentes gêneros textuais escritos e para docentes não só a lecionar em diferentes ciclos e anos de escolaridade (nos $1^{\mathrm{o}}, 2^{\mathrm{o}}$ e $3^{\circ}$ ciclos do Ensino Básico e, preferencialmente, nos $4^{\circ}, 6^{\circ}$ e $9^{\circ}$ anos, por corresponderem a momentos de terminus de um ciclo e de passagem para o seguinte), como também a lecionar diferentes disciplinas curriculares (língua portuguesa, matemática, ciências da natureza).

No que se refere, especificamente, ao modelo de formação implementado, estas formações certificadas para o ensino da escrita, asseguradas por investigadores/formadores do próprio projeto, além de serem pautadas pela própria relevância assumida pelos gêneros textuais, encontram-se, inclusive, em homologia com a própria Sequência de Ensino (PEREIRA; CARDOSO, 2013), fortemente devedora da Sequência Didática do Grupo de Genebra (DOLZ; NOVERRAZ; SCHNEUWLY, 2001), em termos da forma como se encontra estruturada. $\mathrm{O}$ esquema seguinte procura traduzir e sintetizar a estrutura global do desenvolvimento de uma sequência de ensino.

\section{Quadro 1 - Sequência de ensino}

\begin{tabular}{|c|c|c|c|}
\hline \multicolumn{4}{|c|}{$\begin{array}{l}\text { Sequência de ensino } \\
\text { A produção de textos escritos }\end{array}$} \\
\hline Pré-intervenção & Abertura & Desenvolvimento & Fechamento \\
\hline $\begin{array}{l}\text { Caderno de } \\
\text { encargos do gênero } \\
\text { textual }\end{array}$ & $\begin{array}{l}\text { Apresentação da } \\
\text { situação de } \\
\text { comunicação } \\
\text { Produção textual } \\
\text { inicial } \\
\text { Definição dos } \\
\text { conteúdos a } \\
\text { ensinar }\end{array}$ & $\begin{array}{l}\text { Módulos (tarefas } \\
\text { focadas em } \\
\text { problemas } \\
\text { específicos do } \\
\text { gênero) }\end{array}$ & $\begin{array}{l}\text { Produção } \\
\text { intermédia (partes } \\
\text { do texto) } \\
\text { Produção textual } \\
\text { final }\end{array}$ \\
\hline
\end{tabular}

Fonte: Elaborada pelos autores deste artigo. 
Assim, em todas as oficinas de formação, houve quatro grandes fases de trabalho, a par de uma permanente atualização dos formandos também em nível teórico. Numa primeira fase, foram escolhidos textos mentores, que foram objeto de uma importante desconstrução, de modo a perceber-se o seu processo compositivo. Fase esta precedida por uma definição do "caderno de encargos do gênero", em que há uma identificação e caracterização das suas principais dimensões, para uma posterior definição das dimensões a ensinar (em determinado contexto e em dado ano de escolaridade). Por outro lado, foram igualmente selecionados textos produzidos pelos próprios alunos, e submetidos a uma posterior análise, de modo a proceder-se a uma identificação de algumas das principais dificuldades reveladas e de algumas das mais recorrentes capacidades que os alunos já possuem. Passou-se, em seguida, à construção de módulos de ensino, com o apoio dos formadores, e construídos numa perspetiva de progressão entre ciclos, que passaram a constituir-se como sequências de ensino a aplicar em sala de aula, e sobre o gênero textual trabalhado. Depois da sua aplicação in loco, foram estas mesmas sequências de ensino objeto de análise e de reflexão por parte de investigadores, formadores e professores. Aduza-se, ainda, que, também em todas as formações, foram recolhidas produções textuais iniciais - quando do começo da formação - e produções textuais finais, a fim de aferir a evolução registrada nos textos dos discentes e apresentando, assim, algumas recomendações atinentes ao ensino e à avaliação da produção textual escrita.

\subsection{Gêneros de Texto em Ensino - Por} uma formação continuada cooperativa para o desenvolvimento do processo educativo de leitura e produção textual escrita no Ensino Fundamental

O projeto "Por uma formação continuada cooperativa para o desenvolvimento do processo educativo de leitura e produção textual escrita no Ensino Fundamental" - também conhecido por "Gêneros de Texto em Ensino” (CAPES/Inep-Edital 38/2010) (2011-2014) - pretende articular conhecimentos acadêmicos, profissionais e experienciais sobre o ensino da língua portuguesa, com vista ao desenvolvimento das competências de leitura e de produção textual dos alunos desse nível de ensino. Atuando em nível municipal, numa parceria entre a Secretaria Municipal de Educação de Novo Hamburgo (Rio Grande do Sul, Brasil) e o Programa de Pós-Graduação em Linguística Aplicada da Universidade do Vale do Rio dos Sinos (Unisinos), essa proposta formativa é desenvolvida em ação, sendo os docentes os principais atores, que permanentemente refletem sobre as suas próprias práticas. E, em todo este processo, não se trata apenas de colocar o professor em contato com as teorias de linguagem que sustentam, teoricamente, este modelo de formação (assim como com os próprios documentos oficiais do ensino brasileiro, como é o caso dos Parâmetros Curriculares Nacionais e das próprias avaliações de larga escala a que são submetidos os alunos do ensino fundamental, como a Prova Brasil). ${ }^{4}$ Trata-se, igualmente, de explorar essas mesmas teorias, de modo a ajudar os docentes a minimizar as possíveis frustração e impotência para lidar com teorias que desconhecem (KLEIMAN, 2000).

Em relação ao processo propriamente formativo, procede-se, por exemplo, através de blended learning, à leitura e à discussão das referidas teorias, que os docentes intentam aplicar nos materiais didáticos desenvolvidos para as suas práticas em sala de aula. E da articulação dos diferentes saberes trazidos à discussão coletiva e da própria ressignificação dos mesmos pelos diferentes atores desta formação, emergiu, de uma construção coletiva, a proposta de trabalho intitulada "projeto didático de gênero" (GUIMARÃES; KERSCH, 2012b). Nesta proposta, que parte da conhecida noção de sequência didática (DOLZ; NOVERRAZ; SCHNEUWLY, 2004), influências advindas dos estudos do letramento - como os próprios projetos de letramento (TINOCO, 2008) - conduziram o grupo à proposta de que práticas de leitura também fossem incorporadas às próprias práticas de produção textual das sequências didáticas construídas. Mais especificamente, e na ótica dos estudos de letramento, as práticas de leitura e de escrita que compõem um projeto didático de gênero emergem (ou devem emergir) de outras práticas sociais da comunidade em que os alunos estão inseridos (partindo, assim, da realidade discente, mas não ficando

4 Para mais informações, consultar, por exemplo, Guimarães e Kersch (2012a). 
circunscrita a ela). O projeto didático de gênero, a funcionar, assim, como um termo "guarda-chuva", compreende então não só um trabalho didático de ensino da língua materna que quer que o aluno domine o próprio género trabalhado, como também pretende, à semelhança dos projetos de letramento, a construção de uma aprendizagem em que os alunos consigam dar conta de uma prática social relacionada com o gênero trabalhado no projeto didático de gênero em questão.

Para a formação de mais de 50 professores de língua portuguesa, entre os anos de 2011 e 2013, foi instituída uma dinâmica semestral de trabalho, tanto com encontros presenciais, mensais, para a discussão de conceitos e ideias, como também com encontros semanais, através da plataforma virtual Moodle. A cada semestre, os docentes participaram num módulo de formação continuada que versava sobre um dos domínios de agrupamentos de gêneros propostos por Schneuwly e Dolz (2004): em 2011, foi trabalhado o domínio do instruir; em 2012, os domínios do argumentar e do narrar; em 2013, os domínios do expor e do relatar. Em cada semestre, foram também trabalhados conceitos essenciais para a elaboração de projetos didáticos de gênero, tais como: i) gêneros de texto; ii) letramento; iii) modelização e transposição didática; iv) análise linguística; v) leitura e produção textual; vi) avaliação. Ao longo das 60 horas de formação por semestre, os professores também tinham de desenvolver um específico projeto didático de gênero relacionado com o domínio de agrupamento trabalhado naquele período e a apresentar, no final desse mesmo módulo, ao coletivo, para discussão da proposta e dos seus resultados (quando tinha já ocorrido a aplicação em sala de aula).

Como resultados (preliminares) desta formação, além do vasto conjunto de materiais didáticos construídos pelos professores para o seu próprio contexto de atuação, a partir de conceitos e de metodologias de ensino que relacionam as pesquisas acadêmicas desenvolvidas na área da linguística aplicada com o trabalho docente da rede pública de ensino de Novo Hamburgo, a verdade é que neste modelo de formação continuada e cooperativa o professor é um sujeito ativo, implicado na (co)construção da sua formação e no desenvolvimento da sua profissionalidade. Foi por meio da cooperação, na interação com os alunos e pares, que os professores procuraram encontrar respostas e soluções para os desafios de seu trabalho. E, ao cooperarem, e a operarem em conjunto, os resultados alcançados certamente superaram os limites da comum formação continuada para o ensino da escrita, já que consideramos que o agir docente é em grande parte responsável pela qualidade do ensino.

\section{Para uma formação docente de qualidade}

Apesar da complexidade associada à formação de profissionais de ensino, procuraremos agora agregar algumas dimensões responsáveis pelos resultados positivos dos projetos anteriormente descritos (GAGNON; DOLZ, 2009). Antes de mais nada, a formação de professores não se compagina com intervenções pontuais e nem deve surgir de forma descontextualizada, em relação aos respectivos contextos de trabalho. Por outro lado, esta formação deve também integrar professores e investigadores pertencentes a diferentes instituições e com diferentes saberes. ${ }^{5}$ Por outro lado, uma formação que compreenda momentos de aquisição de saberes teóricos e momentos de reflexão sobre as próprias experiências levadas a cabo em sala de aula. Além disso, a construção de um modelo formativo centrado na ação didática propriamente dita, com identificação das principais dificuldades de ensino e de aprendizagem, a fim de serem construídos módulos de formação sobre as mesmas, é também outra exigência desse modelo de formação. Tal como a investigação tem ainda evidenciado (GRAÇA, 2010), no centro dos processos de formação deve estar, igualmente, a própria preocupação com a concepção e com a organização de dispositivos de ensino da escrita rigorosos e fortemente

5 A este propósito, conclui Inês Sim-Sim (2012, p. 57): "O que o Programa Nacional de Ensino do Português nos ensinou é que a eficácia da formação depende da coerência e consistência interna dessa formação, que deve ser intensiva, prolongando-se num espaço temporal determinado, centrada em conteúdos curriculares bem definidos, ter lugar na escola, especificamente na sala de aula, e ocorrer num ambiente de cooperação entre pares [...]. A adesão voluntária dos docentes, o envolvimento dos órgãos de gestão (pedagógica e administrativa) do agrupamento de escolas, a estreita ligação com especialistas, designadamente de instituições de ensino superior, são factores determinantes no sucesso da aprendizagem profissional de docentes em exercício." 
sustentados, em nível teórico, e prevendo uma atuação em diferentes frentes, tais como: construir instrumentos facilitadores do processo escritural, elaborar critérios de avaliação pertinentes, definir instruções de escrita adequadas, analisar procedimentos de escrita de cada aluno - no sentido de lhe proporcionar uma relação positiva com o saber escrever -, criar instrumentos de registo das aulas e analisar as interações didáticas. Os processos de formação devem, ainda, incluir professores de diferentes níveis de ensino, permitindo uma análise dos textos de níveis inferior e superior, favorecendo um olhar analítico mais fino e rigoroso e contribuindo para determinar a própria progressão dos conteúdos. Os modelos formativos apresentados também compreendem sessões de trabalho de natureza oficinal, em que é solicitada aos formandos a reescrita reflexiva de textos autênticos de alunos, com vista a uma sua melhoria, colocando-se depois em comum as principais estratégias mobilizadas. Além disso, uma intervenção pedagógica e didática para a escrita, levada a cabo através de uma reflexão sobre dispositivos que recubram o processo de escrita nas suas diferentes fases, é também susceptível de induzir a própria consciencialização da existência de múltiplas habilidades linguísticas implicadas em vários domínios, e que se projetam, ao mesmo tempo, de uns para os outros. Uma formação para a escrita também tem de formar docentes que sejam, eles mesmos, escreventes, praticantes da produção de todo o tipo de textos (PEREIRA; CARDOSO, 2010). Afinal, é deveras importante desenvolver o conhecimento profissional dos professores por meio de tarefas de escrita, como se sabe (VANHULLE, 2009). Se o professor não tomar também ele contato com os problemas que a escrita coloca, como poderá ser capaz de explicitar aos alunos o processo de escrita? O docente tem, assim, de se tornar escrevente reflexivo e confrontar a sua escrita com a de outros. Nas palavras de Nonnon (1998, p. 155), quando se refere aos diferentes textos que os professores de francês têm de produzir nas provas de concurso para a docência, "a construction et la validation d'une compétence des enseignants en matière de textes s'opère, donc, à travers des expériences textuelles, plus au moins orientées autour de trois pôles: epistémique, identitaire, pragmatique, au sens de régulation de l'action professionnelle", tais como sínteses de textos de didática, descrições analíticas de textos de alunos e descrições comparativas de documentos também didáticos. Esta formação deveria potenciar, igualmente, o próprio ensino da produção de textos em diferentes disciplinas, apostando-se num ensino em que as abordagens textuais e as questões dos gêneros de texto sejam também elas essenciais no ensino e na formação:

Pensando-se ainda nos efeitos dos princípios comuns às abordagens discursivas para o ensino, pode-se dizer que, dessa perspectiva, o ato de ensinar, no âmbito da disciplina Língua Portuguesa, implica contribuir para que o aluno utilize a língua(gem) de forma eficaz, em função dos gestos de leitura que realiza ao atribuir propósitos às acções linguageiras de seu enunciatário e em função das estratégias através das quais materializa seus propósitos, em ações também linguageiras. Isso significa dizer que ensinar e aprender uma língua é, desse ponto de vista, uma das atividades através das quais o aluno se sociabiliza, construindo e reconstruindo sua competência para agir nas interações verbais das quais participa. (MATÊNCIO, 2002, p. 2, grifo do autor).

\section{REFERÊNCIAS}

ADAM, J.-M. Textes: types et prototypes. Paris: Hachette, 1992.

ALARCÃO, I. Professores reflexivos em uma escola reflexiva. São Paulo: Cortez, 2003.

BARBEIRO, L.; PEREIRA, L. A. O Ensino da escrita: a dimensão textual. Lisboa: Ministério da Educação - Direcção Geral de Inovação e de Desenvolvimento Curricular, 2007.

BRONCKART, J.-P., BULEA, E.;POULIOT, M. (Ed.). Repenser l'enseignement des langues: comment identifier et exploiter les compétences? Villeneuve d'Ascq: Presses Universitaires du Septentrion, 2005.

BULEA, E. ; BRONCKART, J.-P. Les conditions d'exploitation de l'analyse des pratiques pour la formation des enseignants. Linguarum Arena, v. 1, n. 1, p. 43-60, 2010.

CASTRO, R. V.; SOUSA, M. L. de. Práticas de comunicação verbal em manuais escolares de Língua Portuguesa. 
In: (Org.). Linguística e educação. Lisboa: Colibri/Associação Portuguesa de Linguística, 1998. p. 43-68.

COUTINHO, M. A. Texto(s) e competência textual. Lisboa: Fundação Calouste Gulbenkian-Fundação para a Ciência e Tecnologia, 2003.

DOLZ, J. ; PLANE, S. Formation des enseignants et enseignement de la lecture et de l'écriture: Recherches sur les pratiques. Namur: Presses Universitaires de Namur, 2008.

DOLZ, J. ; NOVERRAZ, M. ; SCHNEUWLY, B. S'exprimer en français: séquences didactiques pour l'oral et pour l'écrit. Bruxelles: De Boeck, 2001.

Sequências didáticas para o oral e a escrita: apresentação de um procedimento. In: DOLZ, J.; SCHNEUWLY, B. Gêneros orais e escritos na escola. Campinas: Mercado de Letras, 2004. p. 95-128.

GAGNON, R. ; DOLZ, J. Savoirs dans la formation des enseignants pour le français langue première: effets de l'universitarisation. Une étude de cas de l'enseignement du texte argumentatif. In : SCHNEUWLY, B. ; HOFSTETTER, R. Savoirs en (trans)formation - Au cœur des professions de l'enseignement et de la formation. Bruxelles: De Boeck, 2009. p. 221-244. (coll. Raisons éducatives).

GRAÇA, L. O papel das ferramentas didácticas nas práticas docentes de escrita. A análise do objecto ensinado numa sequência didáctica do texto de opinião no Ensino Básico. 2010. 648 f. Tese (Doutorado em Didáctica das Línguas) - Universidade de Aveiro, Aveiro, 2010.

GUIMARÃES, A. M. M.; KERSCH, D. F. Caminhos da construção: projetos didáticos de gênero na sala de aula de língua portuguesa. Campinas: Mercado de Letras, 2012a.

A caminho da construção de projetos didáticos de gênero. In: . (Org.). Caminhos da construção: projetos didáticos de gênero na sala de aula de língua portuguesa. Campinas: Mercado de Letras, $2012 \mathrm{~b}$.

KLEIMAN, A. B. O processo de aculturação pela escrita: ensino da forma ou aprendizagem da função? In: KLEIMAN, A. B.; SIGNORINI, I. (Org.) O ensino e a formação do professor. Alfabetização de jovens e adultos. Porto Alegre: Artmed, 2000. p. 223-243.

KOCH, I.; ELIAS, V. M. Ler e compreender: os sentidos do texto. São Paulo: Contexto, 2006.

MATÊNCIO, M. L. M. Abordagens do discurso e formação de professores de português. In: SIMPÓSIO SOBRE ANÁLISE DO DISCURSO, 2., 2002, Belo Horizonte. Anais... Belo Horizonte: UFMG, 2002.

NONNON, E. Quelle transposition des théories du texte en formation des enseignants. Pratiques, n. 97-99, p. 153-170, 1998.

PEREIRA, L. A.; CARDOSO, I. Os textos de reflexão (livre) em contexto de formação de professores de escrita: Que género? Que mundos? Que desafios? In: ANDRADE, A. I.; PINHO, A. S. (Ed.). Línguas e educação: práticas e percursos de trabalho colaborativo. Perspectivas a partir de um projecto. Aveiro: Universidade de Aveiro, 2010. p. 133-156.

PEREIRA, L. A.; CARDOSO, I. (Coord.). A reflexão sobre a escrita. O ensino de diferentes géneros de textos. Aveiro: Universidade de Aveiro, 2013.

ROLDÃO, M. do C. Formar para a excelência profissional - pressupostos e rupturas nos níveis iniciais da docência. Educação \& Linguagem, São Bernardo do campo, v. 1, n. 15, p. 18-42, 2007.

RONDELLI, F. La cohérence textuelle: pratiques des enseignants et théories de référence. Pratiques, n. 145/146, p. $55-84,2010$.

SCHNEUWLY, B.; DOLZ, J. Gêneros orais e escritos na escola. Campinas, SP: Mercado de Letras, 2004.

SIM-SIM, I. Desenvolvimento profissional no ensino da língua: contribuições do Programa Nacional de Ensino do Português (PNEP). Lisboa: Colibri, 2012.

TINOCO, G. A. Mundos de letramento de professores em formação no agreste rio-grandense. In: OLIVEIRA, M. do S.; KLEIMAN, A. Letramentos múltiplos: agentes, práticas, representações. Natal: EDUFRN, 2008. p. 63-89.

VANHULLE, S. Des savoir en jeu aux savoirs en "je”. Bruxelles: Peter Lang, 2009.

Recebido em: 11.12.2014

Aprovado em: 23.02.2014 